\title{
The Role of Life Satisfaction and Coping Style in the Relationship between Gratitude and School Belonging
}

\author{
Yuhui Qin ${ }^{1}$, Shishuo Qu ${ }^{2}$, Jianyuan Yan $^{3}$, Xiang Wan ${ }^{4}$ \\ ${ }^{1}$ Department of Psychology, Wuhan University, China \\ ${ }^{2}$ Department of Sociology, Wuhan University, China \\ ${ }^{3}$ Department of Economics and Management, Guangxi University, China \\ ${ }^{4}$ Dpartment of Psychology, Wuhan University, China
}

Keywords: gratitude, school belonging, life satisfaction, coping style

\begin{abstract}
Many researches have already been conducted to study the effect of gratitude. Researchers have found that gratitude positively correlates to mental wellbeing, social integration, traits and performance. However, few researchers illustrated how the gratitude worked in helping students adapt themselves to school climate. This study recruited407undergraduate students to examine the relationships betweengratitude and school belonging. It was hypothesized that Gratitude was associated positively and significantly with life satisfaction and positive coping style, both of which were positively and significantly related to school belonging. And life satisfaction and positive coping style played a mediating role in the relationship between gratitude and school belonging. The hierarchical regression analyses indicated that gratitude could significantly predict positive coping style and more life satisfaction, which played a complete mediating role in the relationship of gratitude and school belonging. This research suggests that the gratitude is an effective intervention in helping students adapt themselves to school climate socially and affectively.
\end{abstract}

\section{Introduction}

Gratitude has a positive impact on classrooms and school settings as a whole (Howells, 2014). Specifically, researchers find that gratefulness can help students adapt themselves to the school climate academically, behaviorally, cognitively and affectively (Froh, Bono, \& Emmons, 2010). Students who have a grateful disposition are more likely to report positive outcomes (Froh \& Bono, 2011; Froh, Emmons, Card, Bono, \& Wilson, 2011). Grateful students tend to make full use of their social network when facing adversity, focus on the experiences that they are thankful for and approach the problem (McCullough, Emmons, \& Tsang, 2002; Wood, Joseph, \& Linley, 2007), in which case, they are more likely to satisfy a variety of needs in school, deal with things in positive strategies and become competitive both academically and socially. Consequently, gratitude appears to be a vital intervention in helping individuals build up social ties and a sense of connectedness (Froh, Yurkewicz, \& Kashdan, 2009).

\section{Gratitude and school belonging}

Gratitude can be viewed as a trait or an emotion. As for the grateful trait, it can be regarded as a disposition to notice and recognize the positive outcomes brought about by the benefactors. And gratitude is also a pleasant emotion evoked by appreciating the help of others (McCullough et al., 2002; Wood, Froh, \& Geraghty, 2010).

School belonging is regarded as the feeling of being accepted, respected and supported in the school climate in a general sense (Goodenow, 1993). Classmates and faculties are important in the development of school belonging (Hagborg, 1994). And school belonging can be partitioned into three sections: school settings where students feel received and supported, connectedness with peers and teachers and identification with the norms and activities in the school climate (Faircloth \& Hamm, 2005). 
According to the stage-environment fit theory of school belonging, if students can meet their developmental demands in school, they will report stronger school belonging (Eccles et al., 1993). Grateful people are more likely to note and appreciate the positive in life. And they tend to view everything they have as a gift and become grateful towards a number of benefactors instead of taking their help for granted (Wood et al., 2010). Additionally, the participation-identification theory claims that if students successfully participate in the school-based activities, they are more likely to identify with the school climate.

\section{The mediating role of life satisfaction}

Life satisfaction is a cognitive evaluation of the quality of life with a set of self-imposed standards (Shin \& Johnson, 1978). It also refers to subjective wellbeing that is associated with whether individuals are fulfilled with their lives.

Gratitude is related to mental wellbeing strongly and positively while linked to depression and stress in a negative way (Wood et al., 2010). Grateful people will hold favorable attitudes towards friends and teachers, view the world as a hospitable place and experience more positive affect, which is conducive to subjective mental wellbeing towards their lives (Oberle, Schonert-Reichl, \& Zumbo, 2011; Wood et al., 2007)

Besides, based on the stage-environment fit theory of school belonging, students will develop a sense of school belonging when they feel that their needs are satisfied (Wehlage, Rutter, Smith, Lesko, \& Fernandez, 1989). When students have higher life satisfaction, they appear to be academically competitive than those with lower life satisfaction. And they tend to have better social relationships with peers and faculties and feel less stressed (Gilman \& Huebner, 2006). Therefore, life satisfaction appears to prepare students for fitting in school settings academically, socially and mentally.

\section{The mediating role of coping style}

Coping refers to the efforts to deal with the influence of a stressor (Lazarus \& Folkman, 1984). Coping can be partitioned into two categories, approach coping and avoidant coping. Approach coping indicates dealing with the problem directly, strategies of which include planning, reinterpretation and seeking for social and emotional support. Avoidant coping refers to avoidance in problem-solving situation, instance of which involves denial, self-blaming and behavioral disengagement (Wood et al., 2007). In China, approach coping and avoidant coping are also called positive coping and negative coping respectively.

Gratitude is an important factor in helping individuals cope with the problems (Fredrickson, Tugade, Waugh, \& Larkin, 2003). Gratitude is positively correlated with seeking social support, prosocial relationships, openness and positive reinterpretation. They tend to make full use of their social network to support them and turn to others for help when facing adversity. Consequently, they are more likely to possess positive coping style and try their best to solve the problem rather than falling into substance abuse and depression(Wood et al., 2010; Wood et al., 2007).

With positive coping, students are capable of blending into the school climate academically, interpersonally and mentally, which is beneficial for their adjustment to school settings and improvement in a sense of school belonging (Swanson, Valiente, Lemery-Chalfant, \& O'Brien, 2011; Wehlage et al., 1989).

\section{The present study}

The relationships with mental wellbeing is one of the most important issues in school belonging. Recent studies suggest that school belonging is positively correlated with gratitude, life satisfaction and positive coping (Furlong, Froh, Muller, \& Gonzalez, 2013; Swanson et al., 2011; Wood et al., 2010). This study examines three hypotheses. First, gratitude is positively correlated to school belonging. Second, life satisfaction mediates the relationship between gratitude and school 
belonging. Third, positive coping plays a mediating role in the relationship between gratitude and school belonging. We expect that this study can discover the positive relationships among gratitude, school belonging, life satisfaction and coping style. And we believe that for the relationship of gratitude and school belonging, there will be mediating effects of life satisfaction and positive coping.

\section{Method}

Participants and procedure. Four hundred and seven participants (191 males; 216 females; $M$ age $=21.54 ; S D=1.86$ ) were recruited from different cities in China. Data collection started from May 1, 2015 to May 14, 2015. Respondents visited sojump.com and read the instruction before finishing the questionnaire. After that, they had a chance to win a small gift provided by sojump.com. The data were processed via SPSS version 21.0 and AMOS version 21.0

\section{Measures}

Gratitude. Gratefulness was assessed by The Gratitude Questionnaire-6 (McCullough et al., 2002), which has six items, two of which are reverse scored. The score ranges from 1(strongly disagree) to 7(strongly agree). And the Cronbach's alpha is .82, which indicates good internal consistency.

School Belonging.Students' identification with school was assessed by the Undergraduates' School Belonging Scale (Haoqiang, 2010). There are two dimensions consisting of fourteen items. The first dimension is identity belonging, which has six items and refers to students' identification with school. The second one is emotional and spiritual belonging, which has eight items and is related to students' attachment to school. The responses vary from 1 (never) to 5 (always). The Cronbach's alphas of the whole scale, identity belonging and emotional and spiritual belonging are $.85, .79$ and .80 respectively.

Life Satisfaction. The Satisfaction With Life Scale (SWLS) (Diener, Emmons, Larsen, \& Griffin, 1985) evaluated the quality of one's life. The scale is made up of five items and responses of which range from 1 (strongly disagree) to 7(strongly agree). The internal consistency of SWLS is .87 .

Coping Style. The Simplified Coping Style Questionnaire (SCSQ) (Ya-ning, 1998) was applied to appraise the efforts to deal with stressors. The questionnaire has two subscales consisting of twenty items. The first dimension is positive coping (PC), which composes of twelve items and refers to approaching the problem. The second one is negative coping (NC), which involves eight items and indicates avoiding the problematic situation. The responses range from 0 (never) to 3(often). The Cronbach's alphas of SCSQ, PC and NC are .90, .89 and .78 separately.

\section{Results}

Descriptive statistics and correlations of gratitude, school belonging, life satisfaction and coping style are presented in Table 1 . Gratitude, school belonging, identity belonging, emotional and spiritual belonging, life satisfaction and positive coping are correlated to each other significantly and positively. Positive coping is associated positively and noticeably with negative coping. All of correlations are especially significant $(p<.01)$. 
Table 1 Descriptive statistics and correlations of gratitude, school belonging, life satisfaction and coping style

\begin{tabular}{llllllll}
\hline & $M \pm S D$ & GRA & SB & IB & ESB & LS & PC \\
\hline GRA & $5.26 \pm .60$ & & & & & & \\
SB & $3.15 \pm .69$ & $.28^{* *}$ & & & & & \\
IB & $3.43 \pm .75$ & $.33^{* *}$ & $.92^{* *}$ & & & & \\
ESB & $2.94 \pm .73$ & $.22^{* *}$ & $.95^{* *}$ & $.75^{* *}$ & & & \\
LS & $4.13 \pm .65$ & $.31^{* *}$ & $.45^{* *}$ & $.40^{* *}$ & $.43^{* *}$ & & \\
PC & $2.58 \pm .49$ & $.33^{* *}$ & $.48^{* *}$ & $.43^{* *}$ & $.46^{* *}$ & $.48^{* *}$ & \\
NC & $2.16 \pm .54$ & -.08 & .03 & -.01 & .06 & .08 & $.26^{* *}$ \\
\hline
\end{tabular}

Note. $\quad{ }^{* *}<.01,{ }^{*} p<.05$.GRA, SB, IB, ESB, LS, PC, NC are gratitude, school belonging, identity belonging, emotional and spiritual belonging, life satisfaction, positive coping and negative coping respectively.

Then we examine the mediating effect of life satisfaction and positive coping in the relationship of gratitude and school belonging. Firstly, we examine whether the effect of the independent variable (Gratitude) and mediators (Life satisfaction and positive coping) on undergraduates' school belonging via hierarchical regression analyses. The outcomes are shown in Table 2. After controlling the effect of gender and age, gratitude can predict school belonging positively and especially significantly $(\beta=.34, t=4.70, p<.00)$. And after controlling the effect of gender, age and gratitude, life satisfaction is related significantly and positively to school belonging $(\beta=.27, t=4.02$, $p<.00)$; Positive coping is associated with school belonging positively and significantly $(\beta=.45, t=$ 4.92, $p<.00)$.

After that, we use regression analyses to examine the effect of gratitude on life satisfaction and positive coping. The consequences are presented in Table 3. After controlling the effect of gender and age, we find that gratitude can significantly and positive predict life satisfaction $(\beta=.32, t=$ 4.87, $p<.00$ ); gratitude can also link to positive coping in a positive and significant way $(\beta=.30, t=$ $6.09, p<.00)$.

Therefore, gratitude is associated with school belonging positively and significantly. Life satisfaction and positive coping play a mediating role in the process. In Table 2 , we find that when combined with life satisfaction and positive coping, gratitude fail to predict school belonging ( $\beta$ $=.11, t=1.64, p=.10)$, which indicates that life satisfaction and positive coping have full mediating effects in the relationship between gratitude and school belonging. In the relationship between gratitude and school belonging, the mediating effect of life satisfaction is .09, which makes up 29\% of the total effect. And the bootstrap method shows that the $95 \%$ confidence intervals of this mediating process are from .05 to .15; the mediating effect of positive coping is .12, which constitutes $37 \%$ of the total effect. And the bootstrap method shows that the $95 \%$ confidence intervals of this mediating process starts from .08 to .18. The total mediating effect is .21, which makes up $66 \%$ of the total effect. Based on analyses above, we establish a mediating model in Fig 1.

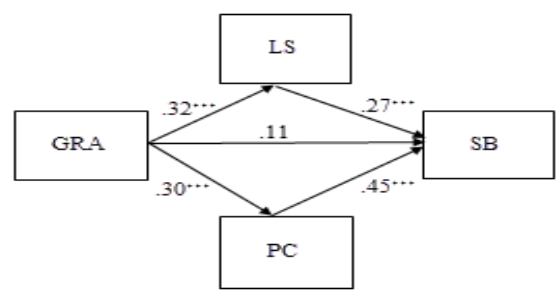

Fig.1 Model of the relationships among gratitude, school belonging, life satisfaction and positive coping.

${ }^{* * *}<.001$. GRA, SB, LS and PC are gratitude, school belonging, life satisfaction and positive coping respectively. 


\section{Discussion}

Grateful students tend to report a feeling of gratitude and treasure even the smallest favor given by others. However, people without a thankful propensity might report fewer grateful moments in their lives (McCullough et al., 2002). Grateful individuals might receive help from family, friends and teachers and then they will regard their environment as hospitable and warm, in which case, they tend to report more satisfaction about the school settings. On the contrary, unthankful students might be untouched by the kindness of classmates and teachers and take their helping hand for granted. In this case, it seems more difficult to meet the demands of people without a grateful disposition. And they are prone to disappointment, which might lead to disengagement in school climate. According to the stage-environment fit theory of school belonging (Eccles et al., 1993), grateful students are more inclined to develop a sense of school belonging.

Besides, gratitude can be viewed as a moral emotion. Grateful individuals will reciprocate those who offer them a helping hand, which might create a beneficent circle of giving and receiving and build up social relationships (Haidt, 2003; Howells \& Cumming, 2012). When students are supported and helped by classmates and teachers, they might want to return the kindness they perceive in school climate and get involved more in activities which are beneficial for the school settings. Based on participation-identification theory of school belonging (Wehlage et al., 1989), grateful students will identify with the school environment and develop a sense of school belonging.

Life satisfaction and positive coping play a mediating role in the relationship between gratitude and school belonging. Individuals who have a grateful propensity incline to focus on the positive side in their lives. And gratitude is positive related to positive emotion, positive social relationships and openness while negatively related to depression and stress (Wood et al., 2010). Grateful students appear to endure the stressful events, look things at the bright side and get along well with others, which contributes to their mental wellbeing.

Gratitude will prepare students for the adaptation to school life academically, behaviorally, affectively and cognitively (Froh et al., 2010). Gratitude is closely related to academic competence (Wood et al., 2010), which might contribute to students' self-efficacy and satisfaction with their performance in school. And gratefulness associates closely with prosocial behavior and social integration (McCullough, Kilpatrick, Emmons, \& Larson, 2001), in which case, students might be content about their social relationships in school. Since grateful people will concentrate on the bright side and have a long list of people to be thankful for (McCullough et al., 2002), they might experience more positive feelings and mental wellbeing. Therefore, gratitude contributes to students' satisfaction towards school settings in various approaches, in which case, students feel that their demands are met and they are more willing to get involved in school activities since they receive positive feedbacks (Faircloth \& Hamm, 2005; Wehlage et al., 1989).

Positive coping also has a mediating effect in the relationship between gratitude and school belonging. Gratitude is an important facilitator in coping style (Fredrickson et al., 2003). Grateful people concentrate on the bright side, appreciate the positive and view the world as a hospitable place, in which case, they may be kind-hearted and inclined to respond to events in a positive way. When faced with adversity, individuals with gratefulness may approach the problem rather than avoiding it (Wood et al., 2007).

Positive coping includes strategies like seeking active planning, social and emotional support and positive reinterpretation ( $\mathrm{Li}$, Zhang, $\mathrm{Li}, \mathrm{Li}, \&$ Ye, 2012; Wood et al., 2007). With positive coping strategies, individuals are more likely to ask others for help and have more opportunities to build up their social network and participate in more school activities. Based on participation-identification theory of school belonging (Wehlage et al., 1989), students who have positive coping strategies will identify more with school climate and derive a sense of school belonging from this process. And they will try to solve the problem rather than avoid it, which helps them engage themselves in the environment and derive more satisfaction in their school lives. According to the stage-environment fit theory of school belonging (Eccles et al., 1993), students with positive coping style will develop a stronger sense of school belonging. 
Gratitude turns out to be a productive intervention in mental wellbeing and adaptation. With gratefulness, students might be more capable of dealing with social relationships in school, becoming a more competitive candidate academically and maintaining their mental wellbeing (Froh et al., 2011; Wood et al., 2010).

\section{References}

[1] Diener, E., Emmons, R. A., Larsen, R. J., \& Griffin, S. (1985). The satisfaction with life scale. Journal of personality assessment, 49(1), 71-75.

[2] Eccles, J. S., Midgley, C., Wigfield, A., Buchanan, C. M., Reuman, D., Flanagan, C., \& Mac Iver, D. (1993). Development during adolescence: the impact of stage-environment fit on young adolescents' experiences in schools and in families. American psychologist, 48(2), 90.

[3] Faircloth, B. S., \& Hamm, J. V. (2005). Sense of belonging among high school students representing 4 ethnic groups. Journal of Youth and Adolescence, 34(4), 293-309.

[4] Fredrickson, B. L., Tugade, M. M., Waugh, C. E., \& Larkin, G. R. (2003). What good are positive emotions in crisis? A prospective study of resilience and emotions following the terrorist attacks on the United States on September 11th, 2001. Journal of personality and social psychology, 84(2), 365.

[5] Froh, J. J., \& Bono, G. (2011). Gratitude in youth: A review of gratitude interventions and some ideas for applications. NASP Communiqué, 39(5), 1.

[6] Froh, J. J., Bono, G., \& Emmons, R. (2010). Being grateful is beyond good manners: Gratitude and motivation to contribute to society among early adolescents. Motivation and Emotion, 34(2), 144-157.

[7] Froh, J. J., Emmons, R. A., Card, N. A., Bono, G., \& Wilson, J. A. (2011). Gratitude and the reduced costs of materialism in adolescents. Journal of Happiness Studies, 12(2), 289-302.

[8] Froh, J. J., Yurkewicz, C., \& Kashdan, T. B. (2009). Gratitude and subjective well-being in early adolescence: Examining gender differences. Journal of adolescence, 32(3), 633-650.

[9] Furlong, M. J., Froh, J. J., Muller, M. E., \& Gonzalez, V. (2013). The role of gratitude in fostering school bonding. National Society for the Study of Education yearbook: Engaging youth in schools: Empirically-based model to guide future innovations. New York, NY: Teachers College Record.

[10]Gilman, R., \& Huebner, E. S. (2006). Characteristics of adolescents who report very high life satisfaction. Journal of Youth and Adolescence, 35(3), 293-301.

[11]Goodenow, C. (1993). The psychological sense of school membership among adolescents: Scale development and educational correlates. Psychology in the Schools, 30(1), 79-90.

[12]Hagborg, W. J. (1994). An exploration of school membership among middle-and high-school students. Journal of Psychoeducational Assessment, 12(4), 312-323.

[13]Haidt, J. (2003).The moral emotions. Handbook of affective sciences, 11,852-870.

[14]Haoqiang, D. (2010). A Study on University Belonging of Undergraduates and Its Impact Factors. (Master), Southwest University Chunking.

[15]Howells, K. (2014). An exploration of the role of gratitude in enhancing teacher-student relationships. Teaching and Teacher Education, 42, 58-67.

[16]Howells, K., \& Cumming, J. (2012). Exploring the role of gratitude in the professional experience of pre-service teachers. Teaching Education, 23(1), 71-88.

[17]Lazarus, R., \& Folkman, S. (1984). Stress, coping and appraisal. New York: Springer. Leary, MR, Maddux, JE (1987). Toward a viable interface between social and clinical/counseling 
psychology. American Psychologist, 42, 904-911.

[18]Li, D., Zhang, W., Li, X., Li, N., \& Ye, B. (2012). Gratitude and suicidal ideation and suicide attempts among Chinese adolescents: direct, mediated, and moderated effects. Journal of adolescence, 35(1), 55-66.

[19]McCullough, M. E., Emmons, R. A., \& Tsang, J.-A. (2002). The grateful disposition: a conceptual and empirical topography. Journal of personality and social psychology, 82(1), 112.

[20]McCullough, M. E., Kilpatrick, S. D., Emmons, R. A., \& Larson, D. B. (2001). Is gratitude a moral affect? Psychological bulletin, 127(2), 249.

[21]Oberle, E., Schonert-Reichl, K. A., \& Zumbo, B. D. (2011). Life satisfaction in early adolescence: Personal, neighborhood, school, family, and peer influences. Journal of Youth and Adolescence, 40(7), 889-901.

[22]Shin, D. C., \& Johnson, D. M. (1978). Avowed happiness as an overall assessment of the quality of life. Social indicators research, 5(1-4), 475-492.

[23]Swanson, J., Valiente, C., Lemery-Chalfant, K., \& O'Brien, T. C. (2011). Predicting early adolescents' academic achievement, social competence, and physical health from parenting, ego resilience, and engagement coping. The Journal of Early Adolescence, 31(4), 548-576.

[24]Wehlage, G., Rutter, R., Smith, G., Lesko, N., \& Fernandez, R. (1989). Dropping Out: Can Schools Be Expected To Prevent It?(From Reducing the Risk: Schools as Communities of Support, P 28-47, Gary G Wehlage, et al,--See NCJ-124151).

[25]Wood, A. M., Froh, J. J., \& Geraghty, A. W. (2010). Gratitude and well-being: A review and theoretical integration. Clinical psychology review, 30(7), 890-905.

[26]Wood, A. M., Joseph, S., \& Linley, P. A. (2007). Coping style as a psychological resource of grateful people. Journal of Social and Clinical Psychology, 26(9), 1076-1093.

[27]Ya-ning, X. (1998). A Preliminary Study of Simplified Coping Style Questionnaire. Chinese Journal of Clinical Psychology, 6(2), 53-54. 